\title{
Hereditary benign intraepithelial dyskeratosis: Is this the first African case?
}

\author{
Loubab Omahsan', Sabah Bazouti', Nassiba Zerrouki', Nada Zizi1, ${ }^{2}$, Siham Dikhaye ${ }^{1,2}$ \\ ${ }^{1}$ Department of Dermatology, Mohammed 6 University Hospital of Oujda - University of Mohammed First - Faculty of \\ Medicine and Pharmacy, Oujda, Morocco, ${ }^{2}$ Laboratory of Epidemiology Clinical Research and Public Health, Medical \\ School, University Mohammed the first, Oujda, Morocco
}

Corresponding author: Dr. Loubab Omahsan, E-mail: loubab.omahsan@yahoo.fr

\begin{abstract}
Inherited benign intraepithelial dyskeratosis (IBID) is a rare genodermatosis, affecting both the oral and conjunctival mucosa. We report a new case of a 10-year-old girl with clinico-histological manifestations of IBID and melkersson rosenthal syndrome. IBID manifests itself by whitish, painless, spongy papules or plaques of varying sizes sitting mainly at the side edges of the tongue. The Melkerson Rosenthal syndrome is a rare disease, to be evoked in the framework of pathologies of the big lips. The association of these two pathologies is unusual.
\end{abstract}

Key words: Inherited Benign Intraepithelial Dyskeratosis; Genodermatosis; Melkerson Rosenthal Syndrome

\section{INTRODUCTION}

Inherited benign intraepithelial dyskeratosis (IBID) is a rare genodermatosis. It is an autosomal dominant disorder affecting both the oral and conjunctival mucosa. IBID is characterized by elevated epithelial plaques on the ocular and oral mucous membranes. It has been reported primarily, but not exclusively, in individuals of American Indian heritage in North Carolina. The melkersson rosenthal syndrome (MRS) is a rare disease, to be evoked in the framework of pathologies of the big lips [1]. This sign is sometimes found in isolation. We report a new case combining both clinical and histological features of IBID and MRS

\section{CASE REPORT}

a 10-year-old girl with first-degree inbreeding with no history of tuberculosis, sarcoidosis or chronic inflammatory bowel disease. It presented from the first days after its birth, a tearing, a photophobia as well as an ocular redness. At the age of 3 , her parents noticed the appearance of whitish patches at the two lateral edges of the tongue, followed later at age 7 by increasing the size of the lower lip as well the tongue. Clinical examination found macrocheilitis (Fig. la) of the lower lip evolving by thrust and incomplete remission, and macroglossia (Fig. 1b) surmounted at the lateral edges by multiple whitish, linear, spongy, painless and undulating plaques (Fig. lb). The ophthalmologic examination noted superficial corneal neovascularization (Fig. lc), as well as two small bilateral whitish opacities (Fig. ld) . In view of this clinical manifestations, an IBID was strongly suspected. Two biopsies at the tongue and lower lip were performed, showing signs for IBID and epithelioid and gigantocellular granulomas with no fibrinoid necrosis or caseins leading to MRS. An exhaustive assessment of tuberculosis and sarcoidosis was without anomalies.

\section{DISCUSSION}

IBID is a hereditary condition, the symptoms of which appear in early childhood and predominantly affecting descendents of Haliwa-Saponi Native Americans [2]. They appear as whitish, painless, spongy papules or plaques of varying sizes, reaching any part of the

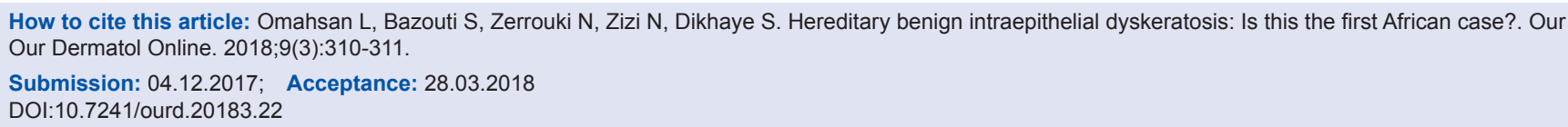




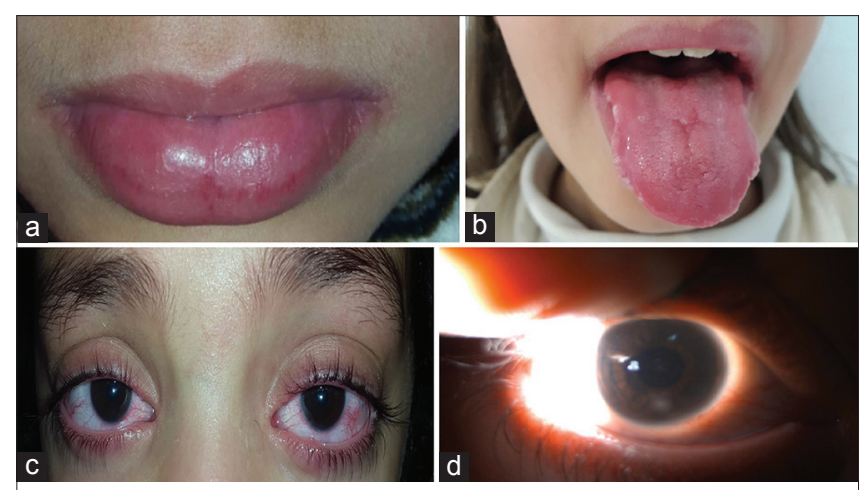

Figure 1: a: Macrocheilitis, b: Macroglossia and multiple whitish, linear, spongy, painless and undulating plaques, c: Superficial corneal neovascularization, d: Corneal opacity

oral cavity. Ocular lesions are typically bilateral, associated with tearing, photophobia, and corneal neovascularization as well as corneal opacities. The affection of the oral and conjunctival mucosa shows the same clinical aspect: Dyskeratosis, parakeratosis and acanthosis of the stratified squamous epithelium. Cells appearing to be engulfed by normal cells, "cellwhithing-cell" pattern can also be seen [3]. The genetic study makes it easy to retain the diagnosis (duplication 4q35), but is not essential [4]. Several medical and surgical treatments have been proposed, but none has proved quite effective [2]. MRS is a rare disorder consisting of a triad of persistent or recurrent orofacial edema, relapsing facial paralysis and fissured tongue. It is rarely possible to observe all aspects of the classical triad at the same time, since these symptoms may appear in different times of life cycle [5]. In our case, we retained the diagnosis of MRS because of the association of macrocheilitis and granulomatous macroglossia. The question of a link between the MRS and the IBID is mentioned in our patient.

\section{CONCLUSION}

According to our knowledge, we report the first case of association of IBID and MRS. Is it a rare association, or an entity in its own right?

\section{ACKNOWLEDGEMENTS}

- We would like to thank Dr. Charif Iliass certified in medical English for his English translation.

- We would also like to thank Pr Rimani Mounia for his expertise in anatomopathology.

\section{CONSENT}

The examination of the patient was conducted according to the Declaration of Helsinki principles.

\section{REFERENCES}

1 Liu R, Yu S. Melkersson-Rosenthal syndrome: a review of seven patients. J Clin Neurosci. 2013;20:993-5.

2 Bui T, Young JW, Frausto RF, Markello TC, Glasgow BJ, Aldave AJ. Hereditary Benign Intraepithelial Dyskeratosis: Report of a Case and Re-examination of the Evidence for Locus Heterogeneity. Ophthalmic Genet. 2016;37:76-80.

3 Baroni A, Palla M, Aiello FS, Ruocco E, Faccenda F, Vozza A, Satriano RA. Hereditary benign intraepithelial dyskeratosis: case report. Int J Dermatol. 2009;48:627-9.

4 Rivera-Serrano CM, Man LX, Klein S, Schaitkin BM. MelkerssonRosenthal syndrome: a facial nerve center perspective. J Plast Reconstr Aesthet Surg. 2014;67:1050-4.

5 Basman A, Gumusok M, Degerli S, Kaya M, Toraman Alkurt M. Melkersson-rosenthal syndrome: a case report. J Istanb Univ Fac Dent. 2017;51:42-5.

Copyright by Loubab Omahsan, et al. This is an open-access article distributed under the terms of the Creative Commons Attribution License, which permits unrestricted use, distribution, and reproduction in any medium, provided the original author and source are credited.

Source of Support: Nil, Conflict of Interest: None declared. 